\title{
COMPACTION OF METAL-CERAMIC POWDER MIXTURES. PART.2 (OVERVIEW)
}

\author{
Ileana Nicoleta Popescu ${ }^{1 *}$ and Ruxandra Vidu ${ }^{2}$ \\ ${ }^{1}$ Valahia University of Targoviste, Faculty of Materials and Mechanics \\ Engineering, Campus, 13 Aleea Sinaia, 130004, Romania. \\ ${ }^{2}$ California Solar Energy Collaborative, University of California, Davis, 1, \\ Shields Ave, Davis, USA. \\ *pinicoleta24@yahoo.com
}

\begin{abstract}
In the second part of paper are presented the old and new compression equations that describe the densification mechanism of one phase (metal/ceramic) powders or two-phase metal-ceramic powders during compaction and also the effect of ceramic particles additions in metallic matrix quantified by densification equations or compaction models. We studied the applicability of compaction models on different metal-ceramic powder mixtures for better understanding the possibilities and limitations of metal-ceramic powder compaction.
\end{abstract}

Keywords: Metal-Ceramic Powders, Composites, Empirical compression equations, Classical models of compaction

\section{Introduction}

The compaction of metal-ceramic powder mixtures, in contrast to the pressing of a single metallic or ceramic phase, requires special attention, taking into account a number of aspects such as:

(i) the different deformation of the metallic powder particles from the ceramic particles, the different (non-uniform) distribution of the loads during the pressing (the hard-ceramic particles take on most of the loads compared to the soft metal ones),

(iii) the size of particles,

(iv) the shape of particles, and

(v) the granulometric distribution of them.

As a result, it is necessary to study qualitatively and quantitatively both the degree of densification of materials from metallic or ceramic powders compared to those in metal-ceramic mixtures. In order to better quantify the phenomena occurring during their processing, a mathematical description of the pressing process of the powder mixtures is required, taking into account: powder specific characteristics, pressures and equipment used.
The mathematical descriptions of the compaction process (powder compression equations) express the theoretical and experimental relationships between density applied pressure, strength - density of the consolidated material, their pressing conditions and the different properties of the powders (composition, the morphology of the powders, granulometric distribution, apparent/tap density, porosity, compressibility and fluidity) using correction factors [1-17].

The interest in powder compaction equations was initially motivated by a practical problem - the need to be able to predict the compaction pressures to achieve a certain density, in order to provide the optimum required properties to the green compact and implicit to the final product.

Over time, numerous researchers (Jones, Walker, Shapiro, Kolthoff, Konopicky, Balshin, Heckel, Cooper, Eaton, Kawakita, Lüdde, Athy, Tanimoto Ge Rong-de, PanelliFilho, Gerdemann, Jablonskietc,) try to find and /or validate a 'simple but adequate' mathematical description of experimentally observed compaction curves and to determine and explain quantitatively the predominant mechanisms of powders' densification, such 
as the compaction stages [4-21]. They proposed a number of empirical equations to characterize compression behaviours and densification mechanisms of one phase (metal or ceramic) powders or two-phase metalceramic powder mixture or composites. Many of proposed equations are valid also for pharmaceutical powders. In the next section are presented the most common models developed by above mentioned researchers.

\section{Compaction behaviour modelling \\ Powder compression equations}

Shapiro - Kolthoff and Konopicky (19471948) [15, 17], Balshin (1949) [5,15, 19] , Heckel (1961) [5,15,19] Cooper-Eaton (1962). [3,6,12,15,17], Kawakita and Lüdde (1971)
[5,15,19]. Later, Ge Rong-de [5,8,10,17] (1991), Panelli and Ambrossinni - Filho (1998) [4,5,7,17], Parilák and Dudrová (2004) [11,14, 18], Castagnet \& Leal Neto 2008 [8] Gerdemann and Jablonski (2011) [9] evaluate the validity and applicability of the old equations to the new powder mixture, at wide range of pressure, composition of mixture, average sizes, etc.) and/ or developed new compaction models.

In Table 1 are shown the compression equations that describe the compaction behaviours and densification mechanisms of one phase (metal or ceramic) powders or twophase metal-ceramic powder composites of all above mentioned researchers.

Table 1 Powder compression equations that describe the compaction behaviours and densification mechanisms of one phase (metal or ceramic) powders or two-phase metal-ceramic powder composites

\begin{tabular}{|c|c|c|}
\hline Authors & Equation(s) & Remarks \\
\hline $\begin{array}{l}\text { Shapiro - } \\
\text { Kolthoff } \\
\text { and } \\
\text { Konopicky }\end{array}$ & $\begin{array}{l}\ln \left(\frac{1}{1-D}\right)=k P+\ln \left(\frac{1}{1-D_{0}}\right) \\
\text { For simplification we note: } \\
k=A_{1} \quad \text { and } \quad \ln \left(\frac{1}{1-D_{0}}\right)=B_{1} \\
\text { Result: } \ln \left(\frac{1}{1-D}\right)=A_{1} P+B_{1}\end{array}$ & $\begin{array}{l}D \text { - relative density at pressure P; } D_{0} \text {-relative } \\
\text { density at "zero pressure"; } A_{l}(k) \text { and } B_{l} \text { are } \\
\text { constants ; the Shapiro and Kolthoff made the } \\
\text { following assumption: the powder mass could } \\
\text { be treated as if it were a solid body subject to } \\
\text { isostatic compression forces. } \\
\text { Konopicky investigated materials: Iron, steel, } \\
\text { magnetite, quartz and magnesite powders; } \\
\text { Shapiro and Kolthoff investigated materials } \\
\text { are: silver bromide powders. }\end{array}$ \\
\hline Bal'shin & $\frac{1}{D}=A_{2} \ln P+B_{2}$ & $\begin{array}{l}D \text { - the relative density of green compact; } P \text { - } \\
\text { applied pressure; } A_{2} \text { and } B_{2} \text { are constants; } \\
\text { Balshin investigated materials: metallic } \\
\text { (electrolytic copper, spherical aluminum } \\
\text { powder) and ceramic powders; }\end{array}$ \\
\hline Heckel & $\begin{array}{l}\ln \left(\frac{1}{1-D}\right)=k P+\ln \left(\frac{1}{1-D_{0}}\right)+B \\
\text { or } \\
\ln \left(\frac{1}{1-D}\right)=A_{3} P+B_{3}+B \\
\text { Result: } \\
\ln \left(\frac{1}{1-D}\right)=A_{3} P+B_{3} \text { at } B=0 \\
\text { Where: } \\
A_{3} \text { or } k=2.08 \times 10^{-6}+0.320 \frac{1}{\sigma_{0}} \\
A_{3} \text { or } k \cong \frac{1}{3 \cdot \sigma_{0}}\end{array}$ & $\begin{array}{l}D \text { - relative density at pressure } P ; D_{0} \text {-relative } \\
\text { density at "zero pressure", or relative apparent } \\
\text { density of the powder; }(1-D) \text { is the pore } \\
\text { fraction. According with Heckel [1], "zero- } \\
\text { pressure" densities means the densities } \\
\text { measured after the compacts are removed from } \\
\text { the die. } \\
\text { After experimental observations, Heckel have } \\
\text { shown that he constant } k \text { (or } A_{3} \text { ) could be } \\
\text { related to the nominal yield strength } \sigma_{0} \text { of the } \\
\text { powdered metal, represented quantitatively in } \\
\text { Eqs. (7) and (8). The constant } B_{3} \text {, which is } \\
\text { always somewhat larger than } l n(1 / l-D o \text { ) } \\
\text { represents the degree of packing achieved at } \\
\text { low pressures (low limit at linearity) as a result } \\
\text { of rearrangement processes before appreciable } \\
\text { amounts of interparticle bonding take place } \\
\text { [1]. In addition, it was found that the constant } \\
B \text { from Eq. (6) is a function of the size and }\end{array}$ \\
\hline
\end{tabular}




\begin{tabular}{|c|c|c|}
\hline & & $\begin{array}{l}\text { shape of the powder particles [1]; } B \text { decreases } \\
\text { as the particle size decreases and as the shape } \\
\text { of the particles becomes more spherical. For } \\
\text { spherical particles, } B \text { is approximately zero } \\
\text { (Eq.6). } \\
\text { Heckel investigated materials: metallic (iron } \\
\text { steel, nickel, tungsten) and ceramic (graphite) } \\
\text { powders [5,15,19]; }\end{array}$ \\
\hline $\begin{array}{l}\text { Cooper- } \\
\text { Eaton }\end{array}$ & $\begin{array}{l}\frac{D-D_{0}}{1-D_{0}}=B_{4} \exp \left(\frac{-A_{4}}{P}\right)+B_{4}^{\prime}\left(\frac{-A_{4}^{\prime}}{P}\right) \\
\text { or } \\
\stackrel{*}{V}=\frac{V_{0}-V}{V_{0}-V s}==a_{1} \exp \left(\frac{-k_{1}}{P}\right)+a_{2}\left(\frac{-k_{2}}{P}\right) \\
\end{array}$ & $\begin{array}{l}D \text { - relative density at applied presure } \mathrm{P} ; D_{0}- \\
\text { relative density at "zero pressure"; } V \text { - } \\
\text { fractional compaction ; } V \text { - volume of compact } \\
\text { at pressure } \mathrm{P} ; V_{0} \text { - volume of compact at "zero } \\
\text { pressure"; } V_{s^{-}} \text {void-free solid material volume } \\
A_{4}, B_{4}, A^{\prime}{ }_{4}, B^{\prime}{ }_{4}\left(a_{1}, a_{2}, k_{l}, k_{2}\right) \text { are Cooper- } \\
\text { Eaton model constants; } B_{4} \text { and } B^{\prime}{ }_{4} \text { represent } \\
\text { dimensionless coefficients indicating the } \\
\text { fraction of theoretical compaction that would } \\
\text { be achieved at infinite pressure by each } \\
\text { mechanism. Cooper-Eaton investigated } \\
\text { materials are ceramic }\left(\mathrm{Al}_{2} \mathrm{O}_{3}\right) \text { powders } \\
{[3,6,12,15,17] \text {. }}\end{array}$ \\
\hline $\begin{array}{l}\text { Kawakita } \\
\text { and Lüdde }\end{array}$ & $\begin{array}{l}\frac{P}{C}=\frac{1}{a b}+\frac{P}{a} \\
C=\frac{V_{0}-V}{V_{0}}=1-\frac{D_{0}}{D}=\frac{a b P}{1+b P} \\
a=C_{\infty}=\frac{V_{0}-V_{\infty}}{V_{0}} \\
\frac{D}{D-D_{o}}=\frac{A_{5}}{P}+B_{5} \\
\text { Where: } \\
A_{5}=\frac{1}{a b} ; B_{5}=\frac{1}{a}\end{array}$ & $\begin{array}{l}C \text { - the reduction of volume by compression; } \\
P \text {-applied pressure; } V_{0} \text { - the initial apparent } \\
\text { volume; } V \text { - the volume under the applied } \\
\text { pressure } P \text {; } D \text { - relative density at presure } P \text {; } \\
D_{0} \text {-relative apparent density of the powder; } a \text {, } \\
b \text { - Kawakita-Lüdde model constants related to } \\
\text { characteristic of the powder. The constant } \\
\text { „a” corresponds to the limit in value of the } \\
\text { relative reduction of the volume by } \\
\text { compression and is equal to the initial porosity } \\
\text { of a powdered mass (Eq. 13), where } V_{\infty} \text { is the } \\
\text { net volume of the powder. The „b” constant } \\
\text { shoud be equal to the reciprocal of the pressure } \\
\text { when the value, C, reaches one-half of the } \\
\left.\text { limiting value ( } C=C_{\infty} / 2\right) \text {; As, B5-constants } \\
\text { (Eqs. } 15,12 \text { ) can be rewritten as (Eq. } 14 \text { ). } \\
\text { The Kawakita's equation has been shown to } \\
\text { give an excellent fit over the widest range of } \\
\text { pressures. The Kawakita and Lüdde Eq. is } \\
\text { widely applicable for metallic, cerramic (i.e. } \\
\text { spherical glass), composites and medical } \\
\text { powders in the fields of powder metallurgy } \\
\text { and pharmaceutics [3,5,15]. }\end{array}$ \\
\hline Ge Rong-de & $\begin{array}{l}\log \left[\ln \frac{1-D_{0}}{1-D}\right]=A_{6} \log P+B_{6} \\
\text { For } D_{0}=0, \text { result the simplified rel.: } \\
\log \left[\ln \frac{1}{1-D}\right]=A_{6} \log P+B_{6}\end{array}$ & $\begin{array}{l}D \text { - relative density at pressure } P ; D_{0} \text {-relative } \\
\text { apparent density of the powder; The } \\
\text { coefficients } \mathrm{A}_{6} \text { and } B_{6} \text { are constants and } \\
\text { represent, the fractional dominance of a } \\
\text { densification mechanism. Ge considered that } \\
\mathrm{D}_{0} \text { approached zero when total pressure } \\
\text { reached zero. Ge investigated materials: } \\
\text { metallic powders (Atomized } \mathrm{Pb} \text { and } \mathrm{Sn} \text {, } \\
\text { Electrolytic } \mathrm{Cu}, \mathrm{Stainless} \text { steel), ceramic } \\
\text { powders (WC, TiC) }[5,8,10,17] \text {. }\end{array}$ \\
\hline
\end{tabular}




\begin{tabular}{|c|c|c|}
\hline $\begin{array}{l}\text { Panelli and } \\
\text { Ambrozio- } \\
\text { Filho }\end{array}$ & $\begin{array}{l}\ln \left(\frac{1}{1-D}\right)=A_{7} \sqrt{P}+B_{7} \\
\text { Where }{ }_{B_{7}}=\ln \left(\frac{1}{1-D_{0}}\right)\end{array}$ & $\begin{array}{l}D \text { - relative density at pressure } P ; D_{0} \text {-relative } \\
\text { density at "zero pressure"; } \mathrm{A}_{7}, \mathrm{~B}_{7} \text {-constants; } \\
\text { The constant } A_{7} \text { stands for plastic deformation } \\
\text { capacity and } B_{7} \text { expresses the density in the } \\
\text { absence of pressure. Panelli and Ambrozio- } \\
\text { Filho are investigated the following materials: } \\
\text { metallic }(\mathrm{Pb}, \mathrm{Sn}, \mathrm{Cu}, \mathrm{Mo} \text {, steel AISI M2 type), } \\
\text { ceramic (TiC, } \mathrm{NbC}, \mathrm{Al}_{2} \mathrm{O}_{3} \text { ) and composite } \\
\text { (AISI M } 2+10 \% \mathrm{NbC)} \text { powders. }\end{array}$ \\
\hline $\begin{array}{l}\text { Parilák and } \\
\text { Dudrová }\end{array}$ & $\ln \left(\ln \frac{1-D_{0}}{1-D}\right)=A_{8} \ln P-\ln B_{8}{ }^{(19)}$ & $\begin{array}{l}D \text { - relative density at pressure } P ; D_{0} \text {-apparent } \\
\text { density of the powder; } \mathrm{A}_{8}, \mathrm{~B}_{8} \text {-constants; The } \\
\text { constant } A_{8} \text { is related to the capacity of powder } \\
\text { particles to undergo plastic deformation, the } \\
\text { constant } \mathrm{B} 8 \text { is related to the geometry of } \\
\text { particles. Parilák and Dudrová investigated } \\
\text { metal powder as Ni-Fe-based alloy } \\
\text { (permalloy) }[11,14,18] \text {. }\end{array}$ \\
\hline $\begin{array}{l}\text { Castagnet \& } \\
\text { Leal Neto }\end{array}$ & $\ln \left(\frac{1}{1-D}\right)=A_{9} P^{0.6}+B_{9}$ & $\begin{array}{l}D \text { - relative density at pressure } P ; \mathrm{A}_{9}, \mathrm{~B}_{9-} \\
\text { constants } \\
\text { Castagnet } \& \text { Leal Neto investigated metal } \\
\text { powders: Niobium and aluminium powder } \\
\text { mixtures [8]. }\end{array}$ \\
\hline $\begin{array}{l}\text { Gerdemann } \\
\text { and } \\
\text { Jablonski }\end{array}$ & $\begin{array}{l}D=D_{0}+A_{10}\left(1-e^{-a P}\right)+ \\
B_{10}\left(1-e^{-b P}\right)\end{array}$ & $\begin{array}{l}D \text { - relative density at pressure } P ; D_{0} \text {-the } \\
\text { initial density, } \\
A_{10} \text { and } B_{10} \text { - parameters that reflect the } \\
\text { relative contribution of powder rearrangement } \\
\text { and work hardening mechanisms to } \\
\text { densification; } a \text { and } b \text { - exponents that reflect } \\
\text { how much pressure } P \text { is required to bring each } \\
\text { mechanism to completion. The maximum } \\
\text { density achievable by compaction alone, } D_{\infty} \\
\text { is the sum of D0, A and B. Gerdemann and } \\
\text { Jablonski invetigated materials are sponge Ti } \\
\text { powders, TiH2 powders, Ti } 64 \text { alloy powders } \\
\text { [9]. On basis of Gerdemann and Jablonski Eq. } \\
\text { (21) Machaka and H. K. Chikwanda [21] } \\
\text { studied Ti powders (sponge Ti, CP TiH2, } \\
\text { Grade } 2 \mathrm{CP} \text { Ti) and also TiH2-SS316L } \\
\text { nanocomposite powders. }\end{array}$ \\
\hline
\end{tabular}

In most used mathematical equations (Shapiro - Kolthoff and Konopicky, Bal'shin, Heckel ) and also in the new equations of $\mathrm{Ge}$ Rong-de , Panelli and Ambrossinni-Filho, Parilák and Dudrová, Castagnet \& Leal Neto or Gerdemann and Jablonski (see Table 1), the $A i(\mathrm{i}=1-3,6-9)$ parameter is used to demonstrate the plastic deformation capacity of the powders or powder mixture and corresponds to the inclination angle of the compressibility curve (the higher $A \mathrm{i}$, the greater the deformation). And the parameter $B i(\mathrm{i}=1-3,6-9)$ can be used to calculate the relative density of the powder at" zero pressure" (Do) or at lowest pressure applied and corresponds to the intersection of the compressibility curve with the ordinate axis.

There is an imprecision inherent in parameter $B_{i}$ because of rearrangement of the powders inside the matrix at the beginning of compaction. However, considering that this rearrangement represents only a small part of the total densification, the parameter $B_{i}$ gives a good approximation of the initial bulk density.

The equation of Bal'shin [5,15,19] in logarithmic form expresses the dependence between relative density and applied pressure (Eq. 3). Konopicky-Saphiro's equation, as well as the Heckel equation, are mainly used 
for metallic powders. These are derived from a differential equation expressing the proportionality between the relative density variations with pressure and porosity Eqs. (1), (2), (4)-(6).

The Kawakita equation $[5,15,19]$ is a commonly used expression to linearize compression data, both from continuous compression experiments and from tapping ones. The basis for the Kawakita equation is the assumption that a powder held in a confined space and subjected to an applied force is a system in equilibrium at all stages of compression, so the product of the increased applied pressure and the volume reduction is constant. The linear relationship (Eq. 11) between $P / C$ and $P$ allows the constants , $a$ " and , $b$ " to be evaluated graphically. Thus, by plotting the curves $P / C=f(P)$, we can get the slope value , $1 / a$," and we put the condition $P=0$ we obtain the value of " $1 / a b$ " on the $P / C$ axis.

Cooper and Eaton introduced a new concept based upon the idea that the size of the pores relative to the size of the surrounding particles determines the kind of pore closing mechanisms [6]. For the sake of simplicity they considered two broad classes of compaction mechanisms; the filling of large holes by particle sliding (involving only slight particle modification by fracture or plastic deformation) and the filling of small holes by plastic flow or fragmentation [6].

\section{Applications of Compaction Models on different metal-ceramic powder mixtures}

A literature survey on the applicability of the densification models indicates that different researchers have used different models to verify their experimental data. There are those who have fitted experimental data to a single model to capture the densification of their powders. For example, Cazzoti et. al [4] for a better understanding of the effect of the $\mathrm{Al}_{2} \mathrm{O}_{3}$ particulate addition on the compressibility of aluminium powder alloys they applied the Panelli Ambrosio equation to linearize the compressibility curves (Fig. 1), while Alizadeh et al. used a modified Heckel equation [17]. Cazzoti observed that the compressibility depends on the powder characteristics and can be altered by hard particles addition, as in the Al MMC particulate reinforced. .

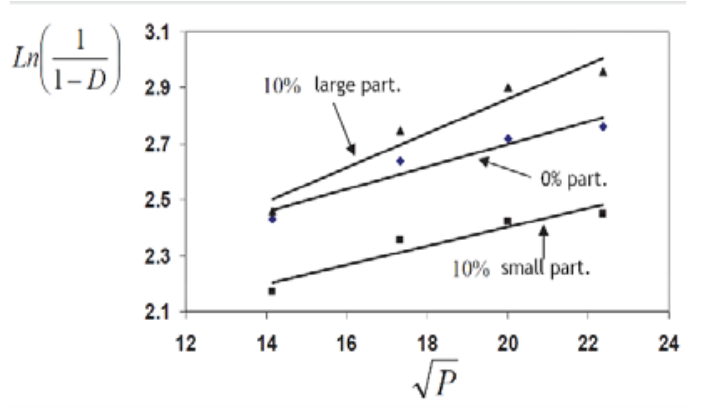

Figure 1. Compressibility curves linearized with Eq. (18) for the unreinforced $\mathrm{Al}$ alloys powders and the $\mathrm{Al}-10 \%$ vol. $\mathrm{Al}_{2} \mathrm{O}_{3}$ mixture powders, for both particle sizes.

The results show that the hard (ceramic) particulates change the $\mathrm{Al}$ powder compressibility and it is extremely dependent of the hard $\left(\mathrm{Al}_{2} \mathrm{O}_{3}\right)$ particulate size. Smaller particles cause a decrease in compressibility (downward movement of the curve), while larger particles cause inverse effect, at the same proportion (10\%) of $\mathrm{Al}_{2} \mathrm{O}_{3}$ particles. Fig. 2 shows that larger sized alumina particles increase the $\mathrm{A}$ parameter when added $\mathrm{Al}_{2} \mathrm{O}_{3}$ to the metal powder alloy, and this increase is quite significant.

Already the smaller alumina particles cause a decrease of the parameter $\mathrm{A}$, and this decrease is more significant for the amount of $10 \% \mathrm{Al} 2 \mathrm{O} 3$.

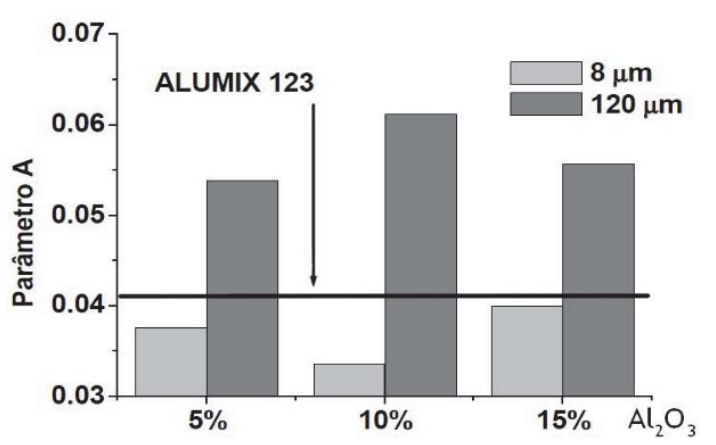

Figure 2. Parameter A for reinforced ALUMIX 123 powder of different sizes and amounts of $\mathrm{Al}_{2} \mathrm{O}_{3}$ [4].

But the other researchers studied metalceramic mixtures /composites and they 
compared more densification equations. For instance, Oliveira in his Thesis [7] has obtained and characaterized the $\mathrm{Fe}-\mathrm{Cu}-$ Diamond system according with Bal'shin, Panelli \& Ambrosio Filho, Rong-De and Heckel densification equations and observed that (Fig. 3) a visible difference was reached between the curves of stages I and II.

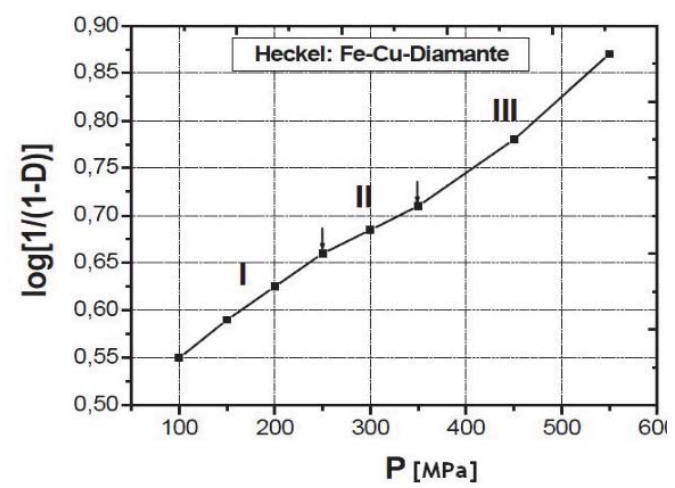

Figure 3 The densification curves of the $\mathrm{Fe}$ $\mathrm{Cu} /$ diamond composite according to the Heckel equation[7].

The two-stage variation occurs at a pressure of $250 \mathrm{MPa}$ - necessary plastic deformation of the particles and fracture at the points of contact, showing precisely the limits of each compaction stage. In this sense, the Heckel equation is the best alternative for the study of composite consolidation $\mathrm{Fe}-\mathrm{Cu}$ / Diamnond powder mixture.

Castagnet [8], after compressibility evaluation of mechanically activated $\mathrm{Nb}-\mathrm{Al}$ powders mixtures with the same above metioned compaction equations, including, Kawakita and Lüdde one, they proposed a new densifiation equation Eq. (20) that fit very well on the $\mathrm{Nb}-\mathrm{Al}$ compressed, with a regerssion coefficient better than 0.9953 .

Hafizpour et al. [12] compared the Heckel, Panelli-Filho, Cooper- Eaton, and Ge models and found that the highest regression coefficient was achieved by the Paneli- Filho equation, while Sivasankaran et al. [15, 20] compared, among others, the Heckel, Ge, Panelli and Ambrosio Filho, Kawakita, etc. compaction models (linear Eqs. (3), (6), (14), (17) and (18) and nonlinear ones (9) presented in Table 1) on nanocrystalline
AA6061 alloy reinforced with $\mathrm{TiO}_{2}$ composite and determined that experimental data was best fitted by the Panelli-Filho model (Fig.4). The different line types show the fitting of experimental data with different compaction equations.

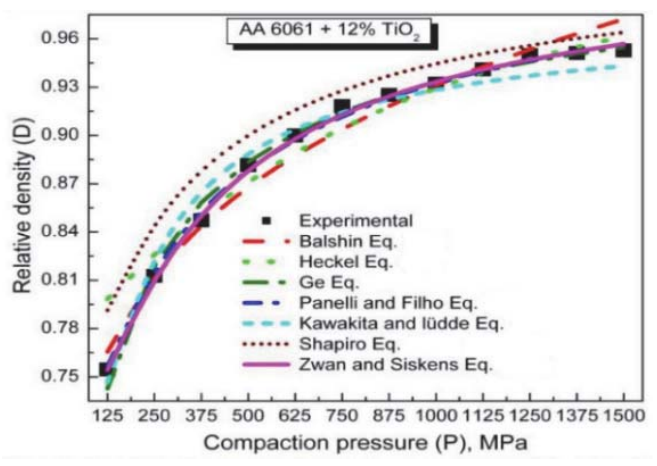

Figure 4 Relative density versus compaction pressure of AA 6061-12 wt.\% TiO2 nanocomposite powder [20].

Moreno and Oliver (2011) [16] working on Al-based powders reinforced with short Saffil fibres showed that the Kawakita and Konopicky equations best fitted the densification behaviour while the PanelliFilho equation was applicable only over a limited compaction pressure range.

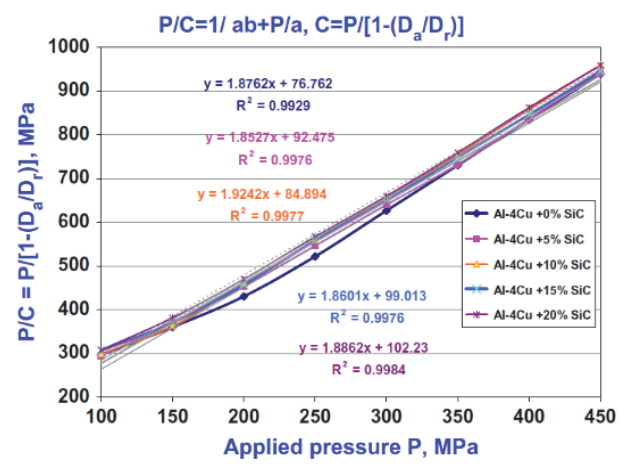

Figure 5 The obtained densification curves according with Kawakita equation (Eq. (11).

Also, Ghita and Popescu [19] studied the compressibility of $\mathrm{Al}-\mathrm{Cu} / \mathrm{SiCp}$ mixture powders and verify on the obtained experimental mixtures the Balshin, Heckel and Kawakita and Lüdde equations, and concuded that that Kawakita models best 
describe (in proportion of 99\%) the compaction behaviour of $\mathrm{Al}-\mathrm{Cu} / \mathrm{SiC}$ composites, used in this experiments, the regression coefficient are better than 0.993 . Thus, using linear regression equation presented in Fig. 5 they [19] could predict the compaction behaviour for pressure higher than $500 \mathrm{Mpa}$, determine the optimum pressure for obtaining maximum densification especially for composites with larger amount of ceramic particles.

\section{Conclusions}

In this paper we reviwed the most commonly and the new compression equations (compaction models) of one phase (metal or ceramic) powders or two-phase metal-ceramic powders (composites) based on relative density -pressure relationship during the stages of compaction. We studied the applicability of compaction models on different metal-ceramic powder mixtures for better understanding the possibilities and limitations of metal-ceramic powder compaction.

\section{References}

[1] R. W. Heckel, Trans. Metall. Soc. AIME, 224 (1962). 1074.

[2]. I. H. Moon ,K. H. Kim, Powder Met., 27(

2) (1984). 80

[3] T. Çomoğlu, J. Fac. Pharm, Ankara, 36 (2) (2007)123.

[4] C. Cazotti, J.L.A. Oliveira, J.B. Fogagnolo, 17o Proceedings of CBECIMat, 15 -19 de November, Foz do Iguaçu, PR, Brasil (2006) 7452.

[5] R. Panelli, Thesis, Coordinator Prof. Dr. Ambrosio Fillo, Production of AISI M2 + 10\%Vol. NbC by Mechanical Alloying, Sao Paulo, 1999.

[6] S. Mani, L.G. Tabil and S. Sokhansanj,. Canadian Biosystems Engineering/Le génie des biosystèmes au Canada, 46(2004) 3.55.

[7] Luciano José De Oliveira, Thesis, Processing and Characterization of the $\mathrm{Fe}$ -
Cu-Diamond System for Diamond Wire Pearls Use (in Portugues), Univ. de Estadual do Norte Fluminense, 2005

[8] M. Castagnet, R. B. Falcão, R. M. Leal Neto, $18^{\circ}$ CBECiMat -, 24 a 28 de Novembro de 2008, Porto de Galinhas, PE, Brasil, 6785. [9] S.J. Gerdemann and P.D. Jablonski, Metall. Mater. Trans. A, 42A (2011).1325

[10] Ge Rong-de, The International Journal of Powder Metallurgy, 27 (3) (1991).211.

[11] L. Parilák, E. Dudrová, R. Bidulský, M. Kabátová, Metallurgy World Congress and Exhibition. Euro PM 2004. Vol. 1., Vienna, 17.-21.10.2004. Ed. H. Danninger, R. Ratzi, EPMA 2004, p. 593-598

[12] H. Hafizpour, A. Simchi, S. Parvizi, Advanced Powder Technology 21(3) (2010).273.

[13] A. Miskova, E. Dudrova, H. Brunckova, M. Faberova, R. Bures, PM2010 World Congress - Fundamentals of Pressing, p. 39

[14] R. BUREŠ, M.FÁBEROVÁ, , PM2010 World Congress - Compaction Equipment, p.81

[15]S. Sivasankaran, K. Sivaprasad, R. Narayanasamy, V. K. Iyer, Powder Technol. 209 (1) (2011).124.

[16]. M. Moreno, C. G. Oliver, Powder Technol. 206(3) (2011).297.

[17] C. Machio, R. Machaka, T. Shabalala, H. K. Chikwanda, Materials Science Forum, 828-829 (2015).121.

[18] C.A. Leon, G. Rodriguez-Ortiz, E.A. Aguilar-Reyes, Materials Science and Engineering A 526 (2009).106.-

[19] C. Ghiţă, I.N. Popescu, Comp Mater Sci, 64 (2012). 136.

[20] S.Sivasankaran, PhD Thesis, Coordinator Prof. Dr. R.Narayanasamy Study on Synthesis, Characterization and Workability behavior of nanocrystalline AA6061 alloy reinforced with $\mathrm{TiO} 2$ Composite prepared by Mechanical alloying, NIT,Tiruchirappalli

[21] R. Machaka and H. K. Chikwanda, Metall Mater Trans A, 46 (5) (2015).2194. 